\title{
Oral Pathology
}

National Cancer Institute

\section{Source}

National Cancer Institute. Oral Pathology. NCI Thesaurus. Code C16957.

The branch of pathology focusing on diseases and disorders of the oral cavity. 